ENSAYO

\title{
LA COMICIDAD DEL PRIMER QUIJOTE Y LA AVENTURA DE LOS GALEOTES $(I, 22)$
}

\begin{abstract}
Anthony Close
Este artículo se propone precisar la naturaleza de la comicidad del Quijote de 1605, basándose en el ejemplo concreto del encuentro del loco hidalgo con los galeotes (Don Quijote I, 22). Como las demás aventuras quijotescas de la primera parte, ésta se arraiga en géneros vigorosamente cómicos, de los que se destacan en este caso los pasos de Lope de Rueda y la recién establecida novela picaresca. El capítulo se funda en la contraposición burlesca del quimérico idealismo del caballero, para quien los galeotes son unos pobres desgraciados que merecen su amparo, a la verdadera índole de éstos, que se expresa en una filosofia y estilo propios del inframundo criminal. No obstante esta comicidad elemental, que culmina en el castigo brutalmente ejemplar del error de don Quijote, la aventura conlleva connotaciones subversivas que matizan y trascienden esta ejemplaridad. Mediante una comparación de la aventura con su equivalente en el Quijote de Avellaneda, el artículo reflexiona sobre el por qué de tales resonancias, típicas del ilimitado poder de significación de la novela cervantina.
\end{abstract}

Anthony Close. Catedrático de la Universidad de Cambridge. Especialista en Cervantes y la comedia española del Siglo de Oro, literatura y sociedad renacentista, y teoría crítica en relación con estas materias. Miembro del Comité Ejecutivo de la Asociación Internacional Siglo de Oro (AISO). Autor, entre otras obras, de Cervantes and the Comic Mind of his Age (Oxford University Press), La concepción romántica del Quijote (Ed. Crítica) y La aproximación romántica a Don Quijote (Ed. Crítica).

Estudios Públicos, 100 (primavera 2005). 
$\mathrm{C}$

omo sabe cualquier lector del Quijote, dentro de la esencial continuidad que une la primera parte con la segunda se exhiben rasgos apreciablemente distintos, entre los que se destacan la comicidad más agresiva y polémica de la primera, y el carácter autorreflexivo y metaficcional de la segunda, uno de cuyos temas principales es la inmensa popularidad del precursor. Puesto que el año de 2005 es, en puridad, el cuarto centenario del Quijote de 1605, voy a ocuparme de ese libro, y concretamente de la naturaleza de su comicidad, tomando como ejemplo principal el encuentro de don Quijote con la cadena de galeotes.

Antes de empezar el comentario detallado de esa aventura, que viene en Don Quijote I, 22, conviene situarlo dentro del contexto de la comicidad característica del primer Quijote. Ésta surge de los recurrentes conflictos entre el protagonista y el mundo exterior, más o menos cortados por el mismo patrón y diseñados para poner en ridículo los libros de caballerías. Este género, que disfrutó de enorme popularidad en el siglo XVI español, fue una continuación de los libros de Lanzarote medievales, que pintan un mundo de caballería legendario ambientado en brumosas regiones celtas $\mathrm{u}$ orientales en una época poco posterior a la muerte de Cristo ${ }^{1}$. Es un mundo algo parecido al fantasmagórico del Señor de los anillos, repleto de monstruos, hermosas princesas, sanguinarios gigantes, afligidas viudas y doncellas, torneos, castillos, palacios, encantadores benignos y malvados, y en primer término, heroicos caballeros andantes, que cabalgan por campos y selvas en busca de peligrosas aventuras para poner a prueba su valor y ganar fama. Ahora bien, como sabemos, toda la acción del Quijote presupone la contraposición irónica de dos perspectivas, debido a que para el loco hidalgo cuanto le pasa constituye una gesta maravillosa como las aludidas, mientras que para los personajes cuerdos, incluido Cervantes y el lector, no se sale de la esfera de lo actual, cotidiano, prosaico y natural. Al cabalgar por las tierras de La Mancha en busca de aventuras, acompañado de un campesino tonto de su pueblo que le sirve como escudero, el autollamado don Quijote de la Mancha interpreta cada uno de sus encuentros casuales con viajeros, animales y objetos inanimados en función de lo que suele ocurrir en el mundo fabuloso de los Amadises, forzándoles a participar, quieran o no, en la aventura que ha improvisado en su fantasía. Ante la

${ }^{1}$ Existe ahora una buena introducción a este género, dirigida al lector no especializado: Emilio José Sales Dasí, La aventura caballeresca: Epopeya y maravillas (Alcalá de Henares: CEC, 2004); para una aportación más densa y documentada, el importante trabajo de Sylvia Roubaud-Bénichou, Le roman de chevalerie en Espagne: Entre Arthur et don Quichotte (Paris: Champion, 2000). 
arbitraria y violenta interrupción de sus actividades, estos adversarios reaccionan, dependiendo del caso, o con indignación, o con pánico, o con malicia burlona, o con ciega y terca resistencia, reacciones que provocan al hidalgo primero a cólera, luego a una arremetida furiosa, que resulta normalmente en otro fracaso humillante para él. El dinamismo frenético de estos enfrentamientos es propio del mundo de la farsa, y supone la ruptura total de las normas, relaciones jerárquicas y supuestos del sentido común de los que depende la convivencia social civilizada. A la vez — cosa que no suele ocurrir en la farsa - la anarquía resultante provoca a reflexión, gracias al modo como la cosmovisión delirante si bien ingeniosamente razonada del protagonista se halla infiltrada por residuos de bien intencionada lucidez y apuntalada con amplia erudición y elegante estilo. Al dejar borrosa la frontera entre la razón y la locura Cervantes parece manejar con ambivalente ironía los tópicos comúnmente aceptados de su época, y ha dado pie a lo que pudiéramos llamar la concepción posmodernista del Quijote, articulada por, entre otros, el novelista mexicano Carlos Fuentes, quien defiende que el Quijote empieza por ser una crítica de la lectura que luego pasa a cuestionar radicalmente los supuestos ideológicos de su propio tiempo ${ }^{2}$. Volveremos sobre esta opinión, limitándonos a observar por lo pronto que habría dejado estupefacto a Cervantes, cuyos asertos explícitos, lejos de confirmarla, ni siquiera la sugieren oblicuamente.

La anterior caracterización de las aventuras de don Quijote se aplica en especial a las concentradas en los primeros veintidós capítulos de la primera parte. La aventura de los galeotes remata esta serie, y ejemplifica perfectamente su carácter polémico y burlón. Empieza con una floritura burlesco-grandiosa típica de la estrategia narrativa de Cervantes, que concuerda con la ficción de que él es el mero editor de una grave crónica de las hazañas de un noble caballero español, atribuida al cronista moro Cide Hamete Benengeli. Cito: "Cuenta Cide Hamete Benengeli, autor arábigo y manchego, en esta gravísima, altisonante, mínima, dulce e imaginada historia, que después que entre el famoso don Quijote de la Mancha y Sancho Panza, su escudero, pasaron aquellas razones que en el fin del capítulo veinte y uno quedan referidas, que don Quijote alzó los ojos y vio que por el camino que llevaba venían hasta doce hombres a pie, ensartados como cuentas en una gran cadena de hierro por los cuellos, y todos con esposas a las manos; venían ansimismo con ellos dos hombres de a caballo y dos de a pie; los de a caballo, con escopetas de rueda, y los de a pie, con dardos y espadas"3.

${ }^{2}$ Carlos Fuentes, Cervantes o la crítica de la lectura [1976] (México: Joaquín Mortiz, 1993).

${ }^{3}$ Cito por la edición de Francisco Rico, 2 tomos (Barcelona: Crítica, 1998), p. 235. 
Detengámonos un momento en este pasaje, ya que resume lo esencial de la actitud de Cervantes, como narrador, ante su historia. Benengeli es un personaje manifiestamente absurdo, y a la vez un doble de Cervantes; es la máscara burlesca que él se pone para narrar la fábula. La voz arábiga Benengeli significa aberenjenado o berenjenero ${ }^{4}$, acorde con el origen toledano del personaje, puesto que berenjenero era apodo de los toledanos, y acorde también con el pueblo toledano de Esquivias, donde es probable que residiera Cervantes en la casa solariega de su mujer por las fechas en que escribía este capítulo. Además, la supuesta actitud veraz y elogiosa de Benengeli ante su materia es desmentida por la reputación de mentirosos y desleales asociada a los moriscos, así como por su estatus despreciable dentro de la sociedad española de aquel tiempo. La naturaleza contradictoria del cronista se refleja en el estilo del pasaje, que se ajusta irónicamente a la suposición quijotesca de que semejante crónica será forzosamente "gravísima" y "altisonante", y, a la vez, la subvierte con frívola ligereza, puesto que los tres últimos epítetos, "mínima, dulce e imaginada", desmienten los dos primeros, aludiendo a la verdadera naturaleza de este libro: una amena y entretenida obra de ficción, llena de menudencias risibles. Por otra parte, el pasaje es típico del modo imparcial como Cervantes suele presentar inicialmente las aventuras de don Quijote; se limita a describir los fenómenos percibidos por sus dos héroes sin identificarlos, en parte para hacer comprender al lector por qué el hidalgo los interpreta en función de su locura, pero más específicamente, en este caso, para centrar la atención en las reacciones contrastadas de amo y mozo, dejando que el lector infiera quién tiene razón, y que disfrute de la perversidad cómica de la interpretación quijotesca.

A este pasaje introductorio le sigue un intercambio entre amo y mozo que asienta las premisas del conflicto de opiniones en que se funda el capítulo. En cuanto Sancho ve a esos doce hombres no vacila en constatar lo obvio: "Ésta es cadena de galeotes, gente forzada del rey, que va a las galeras". A lo cual don Quijote contesta: “¿Cómo gente forzada? . . ¿Es posible que el rey haga fuerza a ninguna gente?". La pregunta, que comporta un equívoco entre dos sentidos de "forzada", pasa por alto el sentido

${ }^{4}$ Etimología que parece confirmada por Sancho en Don Quijote II, 2, al anunciar a su amo que la recién publicada crónica de sus hazañas ha sido compuesta por un moro toledano que se llama "Cide Hamete Berenjena", ed. de Francisco Rico, 2 tomos (Barcelona: Crítica, 1998), p. 645.

${ }^{5}$ Véase el preámbulo de Don Quijote II, 3, donde el héroe dice para sí que "cuando fuese verdad que la tal historia hubiese, siendo de caballero andante, por fuerza había de ser grandílocua, alta, insigne, magnífica y verdadera”, suposición matizada de la sospecha de que "de los moros no se podía esperar verdad alguna, porque todos son embelecadores, falsarios y quimeristas", p. 646. 
contextual de "gente forzada del rey", o sea, prisioneros, dándole un sesgo literal y emotivo que concuerda con la suposición de don Quijote de que los galeotes deben de ser víctimas de algún atropello. Pero Sancho corrige escrupulosamente esta perversión semántica: "No digo eso ... sino que es gente que por sus delitos va condenada a servir al rey en las galeras, de por fuerza". Pero el caballero insiste: "En resolución . . . comoquiera que ello sea, esta gente, aunque los llevan, van de por fuerza, y no de su voluntad". Como ya veremos, la frase "de por fuerza, y no de su voluntad" recurre como un estribillo más adelante en el capítulo, y constituye la base justificativa de la intervención quijotesca: una concepción de mundo al revés respecto de la relación de los galeotes con la ley, fundada precariamente en un retruécano.

Las aventuras quijotescas del primer Quijote, incluida ésta, están saturadas de reminiscencias de géneros de carácter vigorosamente cómico: entremeses y otros motivos teatrales, cuentecillos y novelas, chistes, la novela picaresca. La interrogación de los galeotes por parte de don Quijote, que ocupa aproximadamente las dos terceras partes del capítulo veintidós, y tiene por objeto corroborar su idea a priori de que son víctimas de una inmerecida desgracia, tiene una deuda fundamental con el género del entremés, y más concretamente con los pasos de Lope de Rueda y su escuela. En el prólogo a las Ocho comedias y ocho entremeses, publicadas en 1615, Cervantes afirma que, cuando era muchacho, había visto en las tablas a ese famoso dramaturgo y autor de comedias, y recuerda su excelente representación de varios papeles cómicos: rufián, negra, bobo, vizcaíno y otros. En uno de los pasos de Lope, un ladrón (Madrigalejo) se jacta de sus proezas pasadas ante un lacayo incrédulo (Molina), que le echa en cara el haber sufrido en cierta ocasión el infamante castigo público de cien azotes. El personaje se defiende con los siguientes sofismas:

Madrigalejo: ¿Contaron vuestras mercedes los azotes que me dieron?

Molina: ¿Para qué se habían de contar?

..

Madrigalejo: Pues voto a tal, que no daba vez vuelta o corcovo con el cuerpo que no le echase el verdugo un azote de clavo. Mire vuestra merced si es ciento si no fueron más de quince de menos.

Molina: No hay duda de que es ansí.

Madrigalejo: Pues ¿cómo se puede dezir que me dieron cien azotes, faltando al pie de veinte? Tampoco lo quel hombre no sufre por su voluntad no se puede llamar afrenta. Comparación: ¿qué se me da a mí que llamen a uno cornudo, si la bellaquería está en su mujer, sin ser él consentidor? 
Molina: Tenéis razón.

Madrigalejo: Pues ¿qué afrenta recibo yo que me azoten, si es contra mi voluntad y por fuerza? ${ }^{6}$.

Por lo visto, este trozo de diálogo debió impresionar al joven Cervantes, porque, años después, al componer la aventura de los galeotes, adaptó a sus propios fines lo de "contra mi voluntad y por fuerza". Además, de modo más general, el pasaje se anticipa al capítulo quince de la primera parte del Quijote, donde el arrogante hidalgo, que acaba de ser duramente apaleado por los yangüeses, acumula argumentos a cuál más espurio para probar que la paliza no ha sido agravio infamante.

No para aquí la deuda con Lope de Rueda. En el resto del capítulo, Cervantes saca partido de un tipo de humor verbal que aparece en varios pasos del sevillano, engendrado por la situación en que ladrones novicios piden a un colega avezado que les explique el sentido de voces de germanía, o por otra parte, aquella en que el bobo toma en sentido literal alusiones eufemísticas a castigos vergonzosos a los que han sido condenados sus seres queridos, como ser puesto en la picota, azotado, torturado, y da por sentado que se refieren a honores que van a conferírseles ${ }^{7}$. El interrogatorio

${ }^{6}$ Lope de Rueda, Pasos, ed. José Luis Canet Vallés (Madrid: Castalia, 1992), pp. 174-75. Es el paso cuarto del Registro de representantes, que incluye pasos auténticos de Lope, incluido éste, y otros que son contemporáneos, sin ser suyos.

${ }^{7}$ Véase, en la misma edición, el paso segundo de Registro de representantes, incluido entre los de dudosa autenticidad en un apéndice, pp. 295-303, donde el ladrón avezado Cazorla les va explicando a dos novatos, Salinas y Buitrago, el léxico germanesco: "Estad atentos, hijos míos. Nosotros los cursados ladrones, llamamos a los zapatos, calcurros, a las calzas, tirantes, al jubón, justo ....", etcétera (p. 298). Véase también el paso quinto de El deleitoso (pp. 146-153) donde dos ladrones interceptan al simple Mendrugo que lleva una cazuela a su mujer que está presa en la cárcel, "por cosas de aire, dicen malas lenguas que por alcahueta". El diálogo prosigue así (pp. 149-150):

Panarizo: Y decime, ¿vuestra mujer no tiene ningún favor?

Mendrugo: Sí, señor; tiene muchos brazos y la Justicia que hará lo que fuere de razón; y agora han ordenado entre todos que, porque mi mujer es mujer de bien y mujer que lo puede llevar, que le den un obispado.

Honzigera: ¡Obispado!

Mendrugo: Sí, obispado, y an plega a Dios quella lo sepa bien regir, que según dicen ricos quedamos desta vez. Diga, señor: ¿sabe v. m. qué dan en estos obispados?

Panarizo: ¿Sabes qué dan? Mucha miel, mucho zapato viejo, mucha borra y pluma y berenjena.

Mendrugo: ¡Válame Dios! ¿Todo es dan? Yo deseo vella obispesa.

Honzigera: ¿Para qué?

Mendrugo: Para ser yo el obispeso.

Se da un tipo de comicidad muy parecida en la escena del Coloquio de Tymbria en que el simple, Leno, habla de la santidad de su abuela, quemada por bruja en Cuenca. Véanse Obras de Lope de Rueda, 2 tomos (Madrid: RAE, 1908), ii, pp. 84-87. 
a que don Quijote somete a los galeotes se basa en ambos tipos de equívoco. Al preguntarle al primer galeote el motivo de su castigo se extraña de saber que no es más que "por enamorado". El personaje pasa a explicar la naturaleza de este amor: "quise tanto a una canasta de colar, atestada de ropa blanca, que la abracé conmigo tan fuertemente, que a no quitármela la justicia por fuerza, aún hasta agora no la hubiera dejado de mi voluntad". Obsérvese el eco burlón de la dicotomía quijotesca "de por fuerza" / "de su voluntad", así como la parodia de la idea sentimental de que los galeotes no son más que unos pobres desgraciados.

Cervantes se inspira asimismo en otro género, la novela picaresca, que se establece definitivamente a raíz de la masiva popularidad del Guzmán de Alfarache, publicado en dos partes en 1599 y 1604 respectivamente, y destinado a hacerse el reconocido clásico del género. Profundizar en la actitud ambivalente de Cervantes ante la picaresca — curiosa mezcla de fascinación y de distanciamiento- $\mathrm{y}$, por lo que a la aventura de los galeotes respecta, en los sofisticados juegos metaficcionales que practica con el Guzmán y su brillante precursorcillo, Lazarillo de Tormes, nos llevaría demasiado lejos de nuestro camino. Basta constatar que tanto en el capítulo que ahora nos interesa como en una de sus novelas más famosas, Rinconete y Cortadillo, alude lúdicamente a los convencionalismos del género en ciernes, y en un sentido bastante lato, los parodia, sirviéndose de ellos a un tiempo como trampolín para perseguir fines distintos e independientes. El más célebre de los galeotes, Ginés de Pasamonte, es, entre otras cosas, una personificación del pícaro por antonomasia, Guzmán de Alfarache, puesto que, lo mismo que Guzmán, ha escrito sus memorias, y además se propone acabarlas en las galeras, donde Guzmán escribe las suyas ${ }^{8}$. En esta aventura, el nuevo género constituye principalmente para Cervantes un modelo de rasgos que él considera propios del personaje picaresco. Constituye una especie de filosofía delincuente, expresada en un estilo distintivo, que puede resumirse en los siguientes puntos: una actitud despreciativa y desafiante ante las penas y castigos que la ley impone a los criminales; la manera

\footnotetext{
${ }^{8}$ Tradicionalmente, se ha interpretado el conocido trozo de diálogo en que Ginés de Pasamonte hace referencia a la naturaleza de sus memorias, destinadas, según el galeote, a eclipsar el Lazarillo y "todos cuantos de aquel género se han escrito o escribieren" como un acto de enfrentamiento con el nuevo género por parte de Cervantes, y un deliberado rechazo a su naturaleza autobiográfica, incapaz, según los críticos, de dar una forma artísticamente coherente a la experiencia humana y tratarla con la objetividad necesaria. A mi entender, esta interpretación impone un significado demasiado sutil y denso a una alusión chistosa, sin mayor trascendencia, a uno de los rasgos más distintivos del género. Sobre ello, y para las referencias bibliográficas pertinentes, Peter Dunn, Spanish Picaresque Fiction: A New Literary History (Ithaca, New York: Cornell University Press, 1993), pp. 214-215.
} 
frívola y eufemística de tratarlos como fastidios sin importancia; la resistencia estoica al tormento, fundada en la convicción de que "tantas letras tiene un no como un sí"; la concepción cínica de la corrupción y arbitrariedad de los ministros de la ley, desde el juez hasta el más abyecto porquerón. Todo esto se nos presenta como la antítesis burlona del altruismo idealizante de don Quijote, y su suposición de que los galeotes son unos pobres desgraciados.

Lo podemos ejemplificar con el comportamiento del galeote número cinco, que tiene mucho en común con Guzmán de Alfarache, puesto que lleva hábito de estudiante, y se le califica de "muy grande hablador y muy gentil latino [latinista]". Recordemos que Guzmán, que además de tener la labia y la agudeza de un ex truhán profesional, en cierta época de su vida hizo la carrera de teología de la Universidad de Alcalá de Henares, dando prueba de gran talento antes de abandonar sus estudios por enamorarse de la hija de un mesonero. Es más, el delito del galeote cervantino —el haber seducido a dos primas hermanas suyas, y a la vez a dos hermanas con las que no estaba emparentado, de tal modo que la progenie resultante embrolló por completo la genealogía de las dos familias - nos hace pensar en las infidelidades sistemáticas de la abuela de Guzmán que "enredó cien linajes", diciendo y jurando a cada uno de sus amantes que la hija que había parido era suya ${ }^{9}$. El descarado donjuanismo de este galeote lo agrava el estilo despreocupado y lacónico con el que refiere su proceso y la pena que se le impuso, dando por sentado sin más ni más que de haber podido untar manos y manipular enchufes, habría salido impune del tribunal: "Probóseme todo, faltó favor, no tuve dineros, víame a pique de perder los tragaderos, sentenciáronme a galeras por seis años, consentí; castigo es de mi culpa, mozo soy: dure la vida, que con ella todo se alcanza". Guzmán de Alfarache, Pablos de Segovia y los héroes del Rinconete y Cortadillo cervantino exhiben el mismo laconismo factual, staccato y eufemístico, y el mismo estoicismo cínico, en circunstancias similares. Para Cervantes, estos rasgos serían intrínsecos a la imagen de marca del pícaro ${ }^{10}$.

${ }^{9}$ Mateo Alemán, Guzmán de Alfarache, I, i, 2, en la edición de S. Gili Gaya, 5 tomos (Madrid: Espasa Calpe, 1972), i, p. 98.

${ }^{10}$ Guzmán de Alfarache relata de esta manera el sesgo siniestro que iba tomando su proceso: "Mi pleito anduvo. El dinero faltó para la buena defensa. No tuve para cohechar a el escribano. Estaba el juez enojado y echóse a dormir el procurador", Guzmán de Alfarache, II, iii, 7, tomo v, p. 126. Compárese con esto el estilo en que Rinconete refiere el castigo de azotes y destierro que le dieron por ladrón: "Prendiéronme; tuve poco favor, aunque viendo aquellos señores mi poca edad, se contentaron con que me arrimasen al aldabilla y me mosqueasen las espaldas por un rato, y con que saliese desterrado por cuatro años de la corte. Tuve paciencia, encogí los hombros, sufrí la tanda y mosqueo, y salí a cumplir mi destierro, con tanta priesa, que no tuve lugar de buscar cabalgaduras", en la edición de las Novelas ejemplares de Cervantes, ed. Jorge García López (Barcelona: 
El don Quijote de la primera parte es un personaje de impulsos desenfrenados e imprevisibles; no se sabe nunca contra qué o contra quién va a estrellarse. Cuando se imagina involucrado en una aventura caballeresca, se vuelve inmune a la disuasión; la más mínima irritación inflama su ira y lo provoca a agresión. Si dejamos de lado un lúcido intervalo destacado - el discurso de las Armas y las Letras (I, 37-38)-, su inmersión en las quimeras caballerescas es absoluta, haciendo imposible la afable discreción que, en apreciable medida, marcará su trato con los demás en la segunda parte. Casi la única persona con la que establece contacto humano en la primera - el afecto mutuo, el intercambio sincero de confidencias, la caída momentánea de la máscara caballeresca, un trato de familiaridad coloquial — es Sancho. Con intuición maravillosa, Cervantes funda la intimidad que los une, y que permanece inmune a la fricción de sus temperamentos opuestos, en una actitud compartida de escapismo infantil, que proviene de los sueños del amo con una interminable serie de victorias, fama, amor a Dulcinea, y logro de un reino, y los del criado con el gobierno de una ínsula.

Lo imprevisible del personaje tiene, además, un aspecto psicológico. Mientras su intento de imitar en el escenario de la vida real el heroísmo caballeresco de Amadís y Compañía confiere cierta coherencia interna a su personalidad, su locura le sirve a Cervantes de pretexto para atribuirle vaivenes arbitrarios de comportamiento. En la aventura de los galeotes, por ejemplo, su idealismo ingenuo queda desmentido, de modo desconcertante, se trueca en humorismo cáustico con su apología perversa de la utilidad social del oficio de alcahuete, que según él es: "oficio de discretos y necesarísimo en la república bien ordenada, y que no le debía ejercer sino gente bien nacida; y aun había de haber veedor y examinador de los tales, como le hay de los demás oficios, con número deputado y conocido, como corredores de lonja, y desta manera se escusarían muchos males que se causan por andar este oficio y ejercicio entre gente idiota y de poco entendimiento,

Crítica, 2001), p. 166. Véase también Quevedo, El buscón, libro III, capítulo iv, donde Pablos de Segovia relata cómo él y su cofradía lo pasaron en la cárcel.

Por cierto, los rasgos ejemplificados por estos pasajes no nacen con la picaresca, sino que se derivan de la literatura rufianesca del siglo XVI: romances de germanía, la tradición celestinesca, y el ya citado paso de los ladrones de Lope de Rueda (véase la referencia más arriba al segundo del Registro de representantes), donde el avezado ladrón Cazorla expone su filosofía de resistencia estoica al tormento: "habéis de tener tres cosas: disimulación en el rostro, presteza en las palabras, sufrimiento en el tormento, porque todo es un poquito de aire; no hacen sino apretaros unos cordelitos a los pies, y haceros tragar algunos jarrillos de agua; bébese el hombre por su pasatiempo de que tiene gana de beber seis o siete: ¡mira qué maravilla!” No obstante, son Alemán y sus sucesores quienes los llevan a madurez y los plasman en una filosofía y estilo distintivos. 
como son mujercillas de poco más a menos, pajecillos y truhanes de pocos años y de poca experiencia". El ser de semejante profesión honrada es el delito del que ha sido juzgado culpable el galeote número cuatro: un anciano plañidero y llorón de larga barba blanca. Al Siglo de Oro, con su preocupación obsesiva por guardar las apariencias, le resultaba sumamente divertido el elogio burlesco de oficios viles, o bien, el retrato de personajes que los ejercen, y no obstante, alardean descaradamente de su honor y nobleza. El elogio o auto-elogio del alcahuete, alcahueta o rufián era un tópico de las comedias en prosa derivadas de La Celestina, el cual se inicia en el tercer acto de la tragi-comedia de Fernando de Rojas, donde la madre Celestina se enorgullece de su maestría en el oficio: "En esta ciudad nascida, en ella criada, manteniendo honrra, como todo el mundo sabe, ¿conoscida pues no soy?"11. Después, pasa a ser un tópico de la literatura burlesca del siglo XVII ${ }^{12}$. Al ponerlo en boca de don Quijote, Cervantes nos plantea el problema de interpretar sus móviles. ¿Estará hablando en serio? Esto apenas parece creíble. Pero, si se trata de jocosidad satírica, ¿cómo se compadece esta explicación con el idealismo ingenuo que demuestra el personaje en el resto de la aventura? Está claro que, para Cervantes, la locura corta el nudo gordiano de dilemas semejantes, inspirando momentáneamente a su personaje — pese a la incongruencia — la desenfadada articulación de un tópico burlesco.

Nos causa una impresión desconcertante de tipo algo parecido el discurso en el que el auto-elegido abogado de la defensa, después de terminada la interrogación de los galeotes, suplica a los guardas que pongan en

${ }^{11}$ Ed. de Julio Cejador y Frauca, 2 tomos (Madrid: Espasa Calpe, 1968), i, p. 133. Los términos en que don Quijote elogia el oficio del alcahuete se parecen en varios aspectos a los discursos del rufianesco personaje Galterio y de la alcahueta Franquila, en la anónima La Thebayda (1521). Véanse las páginas 92-95, 113, y 124 de la edición de Keith Whinnom y G. D. Trotter (Londres: Támesis, 1968). Por ejemplo, Galterio defiende calurosamente a los malsines o soplones, rechazando indignado la mala fama que se les atribuye: "Pero, ¿por qué dixiste malsines? No quiero consentir esso: antes es oficio de hombres justos y zelosos de concordia. ¿Y qué otro oficio es el del regidor o jurado, salvo mirar que las cosas de su república estén bien governadas, y poner espuelas al corregidor en que castigue los excesos feos y abominables al bien popular, y hazer que con todo rigor se executen?" (p. 93). En la misma comedia, la alcahueta Franquila se jacta de su habilidad en el oficio, comparándose con "los temerosos y no esperimentados, como son las donzellas y personas semejantes, que siempre sus respuestas son cargadas de mil recelos y acompañadas de mi género de temores" (p. 124).

Sobre la figura del alcahuete, Augustín Redondo, Otra manera de leer el "Quijote" (Madrid: Castalia, 1998), pp. 347-361. En este libro Redondo ofrece una interpretación de este capítulo algo semejante a la mía, desde una perspectiva muy influida por las teorías de Mijáil Bajtín. Insiste sobre la naturaleza paradójica de mundo al revés de la comicidad del capítulo. Véanse también las pp. 251-263.

12 Véase la nota de F. Rodríguez Marín a las pp. 173-174 del tercer tomo de su Nueva Edición Crítica del Quijote, 10 tomos (Madrid: Atlas, 1947-1949). 
libertad a sus prisioneros. Igual que el elogio del alcahuete, se trata de una defensa de lo indefensible del mundo al revés; aunque en este caso la inversión de la normalidad racional no cabe atribuirla al humorismo, sino a una mezcla incongrua de compasión empalagosa, casuística ingenua, arrogancia mesiánica, súplicas, amenazas, y máximas emotivas. Estas últimas, en particular, contribuyen a la ambivalencia del discurso, que llevó a Ángel Ganivet en su Idearium español (1897), así como a Miguel de Unamuno en su Vida de don Quijote y Sancho (1905), a interpretarlo como una reivindicación de la justicia ideal en contraposición a los mecanismos fríos e institucionalizados de la ley ${ }^{13}$. Así, para Unamuno, la liberación de los galeotes por parte de don Quijote concuerda con la preferencia de éste - que sería asimismo la de Dios, de la naturaleza, y del pueblo español — por el castigo espontáneo e irreflexivo seguida del perdón. Como bien sabía Unamuno, su concepción idealizada de don Quijote como una especie de Cristo moderno no la compartía Cervantes; el efecto en parte burlesco del discurso lo señala claramente el empalagoso "hermanos carísimos" del comienzo, grotescamente inadecuado a los maleantes a quienes el hidalgo acaba de interrogar, así como los argumentos espurios y tendenciosos expuestos en las diez primeras líneas para apoyar la conjetura de que la desgracia de estos delincuentes es en parte inmerecida. No obstante, no cabe descartar sin más ni más la lectura unamunesca. Las mencionadas máximas, que Unamuno cita abundantemente y constituyen la base de la petición de don Quijote, serían conmovedoras y persuasivas si tuvieran en cuenta las circunstancias. Para encarecer lo razonable de su petición, don Quijote invoca uno de los atributos de la prudencia, que, junto con la fortaleza, la templanza y la justicia, era una de las cuatro virtudes cardinales definidas por la ética de la Antigüedad. Al abogar por la libertad de los galeotes - "me parece duro caso hacer esclavos a los que Dios y la naturaleza hizo libres"- el hidalgo invoca un principio de ley natural que era tema recurrente de los debates escolásticos del Siglo de Oro (Vitoria, Soto, Suárez, Molina) sobre la licitud de la guerra, de la colonización y del dominio de unos sobre otros ${ }^{14}$. Apela también, aunque de modo indirecto, al precepto evangélico: "No juzguéis para que no seáis juzgados" (San Mateo, 7, i), mediante cita del refrán que expresa una idea muy parecida: "Allá se lo haya cada uno con su pecado; Dios hay en el cielo que no se descuida de castigar al malo, ni de premiar al bueno". $\mathrm{Al}$ amonestar a los guardas: "No es bien que los hombres honrados sean

${ }^{13} \mathrm{He}$ manejado la sexta ed. del Idearium español (Madrid: Suárez, 1933), pp. 68-69, y la ed. Austral de la Vida de don Quijote y Sancho, comentario al capítulo 22 del Quijote, pp. 87-93.

${ }^{14}$ Cf. Bernice Hamilton, Political Thought in Sixteenth-Century Spain (Oxford, Clarendon, 1963), p. 35 у passim. 
verdugos de los otros hombres, no yéndoles nada en ello", recurre al mismo principio de clemencia que encarecerá don Quijote al gobernador electo Sancho Panza en sus preceptos de gobierno. No obstante, en este discurso predominantemente lúcido, matiza el precepto con una salvedad importante, olvidada en la arenga a los galeotes y sus guardas: "cuando pudiere y debiere haber lugar la equidad, no cargues todo el rigor de la ley al delincuente, que no es mejor la fama del juez riguroso que la del compasivo" (II, 42). En cambio, la exhortación a los guardas a mostrarse compasivos con los malvados que están a su cargo no es más que un disparate. Así que, cuando don Quijote, tras haber arremetido contra los guardas y puesto en libertad a los prisioneros, más bien por suerte que por sus propios esfuerzos, los reúne alrededor de él y los exhorta arrogantemente a irse cargados de sus cadenas a rendir homenaje a Dulcinea, tiene su merecido: en vez de agradecimiento admirativo, una humillante e interminable pedrada.

El capítulo termina con la imagen brillantemente sugerente de dos figuras verticales y dos horizontales: don Quijote y Rocinante tendidos el uno al lado del otro, y Sancho despojado de su capa junto a su asno, que se queda pensativo, con la cabeza agachada, "sacudiendo de cuando en cuando las orejas, pensando que aún no habían cesado la borrasca de las piedras". Esas orejas son casi el único juicio que se pronuncia sobre lo sucedido, puesto que Cervantes, como suele, no ofrece ninguno, aparte del comentario lacónico sobre don Quijote, "mohinísimo de verse tan malparado por los mismos a quien tanto bien había hecho". En esta frase percibimos un eco de la moraleja de la fábula de Esopo del hombre que cuida una culebra durante todo el invierno, y luego se queja cuando ésta lo pica. En la versión española que conocería Cervantes, reza: "El que faze bien y ayuda al malo ingrato sepa que sera del desagradecido y en lugar de le responder con buena obra le contrariara" 15 .

Así, podemos leer la aventura de los galeotes como una fábula de derechas sobre la locura de hacer bien a los ingratos, idea expresada con sucinta brutalidad por el refrán: "Cría cuervos y te sacarán los ojos". O bien, de acuerdo con Unamuno, la podemos leer como una fábula cristiana sobre el fin de la caridad, que consiste nada más que en ella misma. O bien, con Herman Melville, autor de Moby Dick, la podemos interpretar como una fábula de izquierdas sobre la fraternidad del hombre y el destino lastimoso de empresas utópicas en un mundo hostil e indiferente ${ }^{16}$. Esta virtualidad ilimitada de significados, característica de los grandes mitos, es típica de

${ }^{15}$ Cito por la reedición facsímile de la ed. de 1489 (Madrid: RAE, 1929), pp. xxix-xxx, "del ombre y de la culuebra".

${ }^{16}$ Harry Levin, "Don Quijote y Moby Dick", Realidad, 5 (Buenos Aires, septiembre/octubre 1947), pp. 254-267 (260, 263-266). 
Don Quijote, y es reforzada por la objetividad lúdicamente irónica de Cervantes.

A este respecto es instructivo comparar la aventura de los galeotes con su imitación en la continuación del primer Quijote compuesta por Avellaneda. En el capítulo ocho de la versión apócrifa, el protagonista, ya en Zaragoza, ve a un delincuente al que llevan por las calles montado en un asno, mientras se le inflige una tanda de azotes ${ }^{17}$. Urdiendo en su fantasía una historia de un caballero raptado por enemigos malignos, don Quijote intenta poner en libertad al reo, sin conseguir más que verse desarmado y apresado en seguida por un tropel de guardas y circundantes, y metido acto seguido en la cárcel, con la perspectiva inminente de sufrir el mismo castigo que el hombre que intentó liberar. Sólo consigue evitar esta suerte gracias a la intervención de su valedor aristocrático, don Álvaro Tarfe, quien persuade al juez a soltarle por loco. Es decir que Avellaneda, desde un punto de vista de sentido común respetuoso de la ley, trata la intervención de don Quijote como quimérica e ineficaz, y suprime del todo las connotaciones subversivas y sugerentes de la aventura cervantina. En ésta, surgen de un complejo de factores: los emotivos principios de clemencia y misericordia que invoca don Quijote; las alusiones pasajeras, por tendenciosas que sean, a la arbitrariedad de la ley; la desproporción brutal entre la ofensa de don Quijote y la reacción de los galeotes; sobre todo, el hecho de que, por loca que sea su intervención, consigue su objetivo. Avellaneda mantiene la justicia poética convencional; Cervantes la vuelve patas arriba, y al hacerlo, parece querer decirnos algo.

Pero ¿qué, precisamente, es lo que intenta decirnos? Al intentar contestar la pregunta, conviene no exagerar lo subversivo de la aventura. Ésta, al igual que otras del primer Quijote, se arraiga en la farsa, o en géneros muy afines, valiéndose de la licencia que comúnmente se les concede para dar al traste con las normas sociales. Cuando Cervantes, en su épica en prosa Persiles y Sigismunda, maneja situaciones semejantes a la aventura de los galeotes, como sucede en dos o tres ocasiones en el tercer libro (véanse en especial los capítulos 5-6, y 10), su tratamiento es a la vez más serio y más concordante con los valores convencionalmente establecidos. La misma observación vale para los preceptos de gobierno que don Quijote da a Sancho en la segunda parte, capítulos 42 y 43, donde algunos de los principios edificantes que invoca y aplica perversamente el libertador de los galeotes - en especial, sobre la atenuación de la justicia con la clemencia - vuelven a afirmarse dentro de un contexto que ningún coetáneo de Cervantes hubie-

\footnotetext{
${ }^{17}$ He manejado la edición de Martín de Riquer, 2 tomos (Madrid: Espasa Calpe,
} 1972). 
ra considerado revolucionario ${ }^{18}$. La alegre anarquía desencadenada por la intervención quijotesca le permite a Cervantes dar un desenlace, que, a la vez que castigarla, satisface varios impulsos suyos que son ajenos a la solución convencional de Avellaneda: su suspicacia castizamente española, todavía viva y vigorosa hoy en día, hacia los intrincados trámites y las corruptelas de la ley, junto con la consiguiente simpatía por quienes saben burlar astutamente los mecanismos legales ${ }^{19}$; su preferencia habitual, bien ejemplificada por la actuación de Sancho en Barataria, por un tipo de justicia humana, informal, acorde con el sentido común, que deja de lado trámites puntillosos y suaviza la aspereza con la misericordia ${ }^{20}$.

Así, no cabe considerar la aventura de los galeotes como confirmación de la tesis posmodernista. No obstante, conviene evitar el error contrario, que consistiría en minimizar su potencial sugestivo, semejante al efecto de tirar una piedra pesada a una charca profunda, extendiéndose desde el punto de impacto ondulaciones de cada vez mayor envergadura. Desde que Baltasar Gracián, en su gran alegoría en prosa de la peregrinación vital del hombre, El Criticón (1651-1657), tercera parte, crisi siete, tomó a don Quijote y Sancho como arquetipos de defectos morales contrastados, fanfarronería o esnobismo por un lado, pusilanimidad egoísta por otro ${ }^{21}$, la fábula de Cervantes ha sido interpretada como símbolo de la condición humana por cada época sucesiva, que suele atribuirle un significado acorde con sus propias preocupaciones dominantes. Para el Siglo de las Luces, don Quijote encarnaba cualquier tipo de fanatismo o adhesión a ideas anticuadas; para el siglo XIX, lo ideal en conflicto con lo real; para el siglo XX, la novela impartía una lección de relativismo epistemológico; para el posmodernismo, la deconstrucción del lenguaje, de la historia, y del monocentrismo. Ante

${ }^{18}$ Aparte del principio ya citado, la reprobación del lenguaje injurioso: "Al que has de castigar con obras no trates mal con palabras, pues le basta al desdichado la pena del suplicio, sin la añadidura de las malas razones" (p. 972). Cf. el comportamiento algo semejante del hidalgo en la aventura anterior: "Alzó la vara en alto el comisario para dar a Pasamonte, en respuesta de sus amenazas, mas don Quijote se puso en medio y le rogó que no le maltratase, pues no era mucho que quien llevaba tan atadas las manos tuviese algún tanto suelta la lengua" (p. 244).

19 Cf. El licenciado Vidriera, Novelas ejemplares, pp. 188-189; La ilustre fregona, Novelas ejemplares, p. 397; cf. el desenlace de la interrogación de los dos falsos ex persiles y Sigismunda III, 10, en la ed. de R. Schevill y A. Bonilla, 2 tomos (Madrid: Bernardo Rodríguez, 1914)

${ }^{20}$ Véase (aparte de los consejos de gobierno a Sancho y su misma actuación en Barataria) Don Quijote II, 32, p. 900; El amante liberal, Novelas ejemplares, p. 128; los consejos de Periandro al marido vengativo en Persiles y Sigismunda III, 6.

${ }^{21}$ Véase mi artículo "Gracián lee a Cervantes: La trascendencia de lo intrascendente", en Baltasar Gracián IV Centenario (1601-2001). Actas del II Congreso Baltasar Gracián en sus Obras (Zaragoza, 22-24 de noviembre de 2001), ed. Aurora Egido, María Carmen Marín, Luis Sánchez Laíllo (Zaragoza: Institución Fernando el Católico, 2004), pp. 179-198 (181-182). 
juicios tan caóticamente divergentes, nos preguntamos perplejos: ¿qué le confiere a este libro ya muy viejo, producto de una época muy remota de la nuestra - aun más en el sentido ideológico que en el temporal—, su poder ilimitado de significación?

Intentar contestar esa pregunta en un párrafo final sería una empresa quijotesca, y sin embargo, para eso están los párrafos finales ${ }^{22}$. En un principio - $-\mathrm{y}$ he aquí su novedad revolucionaria en relación con las narraciones en prosa de la época de Cervantes-Don Quijote es un híbrido ambivalente, mezcla de aventura heroica o romántica y su parodia crítica, que a menudo funde las dos cosas. Esto es porque Cervantes se burla de la locura quijotesca y del género caballeresco que personifica desde la perspectiva de una épica en prosa ideal que cumplirá después con la composición de su novela bizantina Persiles y Sigismunda, de la que pueden considerarse adelantos algunas de sus novelas cortas, incluidas las intercaladas en el Quijote. Precisamente por su relación interna y empática con ese tipo de ficciones idealizadas, crea a un héroe que en vez de ser una ridícula caricatura de ellas, constituye una versión que posee, potencialmente, muchos de los requisitos necesarios, echándolos a perder por su adhesión a un modelo anticuado. Así, en el libertador de los galeotes percibimos una versión frustrada y abortiva de Periandro, protagonista del Persiles, la cual nos resulta mucho más interesante y simpática que Periandro precisamente porque, a diferencia de ese mojigato epítome de la virtud, el loco hidalgo, lejos de estar forjado en el molde de la ortodoxia neo-clásica y del decoro cortesano, es un personaje originalísimo, atrayente y estrafalario, que vuelve patas arriba los valores convencionalmente establecidos desde un punto de vista que él defiende con una mezcla de argumentos disparatados y acordes con la razón. De ahí la ambivalencia del personaje. El segundo motivo de la pluralidad potencial de significados del libro - factor que ayuda a explicar dicha ambivalencia, a la vez que la agrava - estriba en la estrategia original que adoptó Cervantes para resolver un dilema que le planteaba el didactismo contrarreformista. La literatura de entretenimiento de aquella época o se identifica de modo categórico con esos objetivos, como hace el Guzmán de Alfarache, o bien se siente obligada a justificar de algún modo el dejar de hacerlo, como La pícara Justina. No obstante, hacer de una obra de entretenimiento una especie de púlpito, a la manera del Guzmán, era una infracción contra el decoro, tanto para la devoción postridentina como para la estética neoclásica; y contra ese tipo de pretenciosidad lanza Cervantes los

${ }^{22} \mathrm{He}$ intentado dar una respuesta más desarrollada en "Por discreto y por amigo": Mélanges offertes a Jean Canavaggio, ed. Christophe Couderc y Benoît Pe1listrandi (Madrid: Casa de Velázquez, 2005), pp. 47-53. 
dardos de su sátira en el prólogo al primer Quijote ${ }^{23}$. En su novela, resuelve el dilema de cómo evitar la frivolidad sin incurrir en el sermoneo, incorporando a su fábula los tópicos serios y edificantes de su tiempo, y a la vez tratándolos de una manera ligera, humorística e idiosincrásica. Así, el libertador de los galeotes invoca el perdón cristiano, la ley natural escolástica, la definición clásica de la prudencia, y el principio jurídico de la equidad - todo eso en apoyo de un pleito disparatado. Por consiguiente, desde en torno a 1700, cuando la distancia temporal empezó a borrar los presupuestos culturales que darían por sentados los coetáneos de Cervantes, los lectores se han preguntado qué pretende y de qué lado está. La tercera razón, relacionada con la anterior, es la naturaleza arquetípica de los dos protagonistas, que se deriva principalmente de la manera en que sus caracteres se conciben como una síntesis concentrada de tipos literarios y folclóricos, sin que se señalen obviamente las alusiones, que son mucho menos trasparentes hoy en día de lo que eran en el Siglo de Oro. Si Baltasar Gracián a mediados del siglo XVII vio en don Quijote una personificación de la presunción vanidosa, esto se debe a que Cervantes combina hábilmente en el personaje, sin llamar la atención sobre las citas, rasgos que toma prestados a conocidos modelos de fanfarronería: el miles gloriosus de la comedia latina, los lacayos y rufianes jactanciosos de sus continuaciones renacentistas, los paladines bravucones de la tradición ariostesca, el escudero patológicamente presumido del Lazarillo de Tormes. El eclecticismo omnialusivo es un aspecto inherente a la personalidad de don Quijote, puesto que va enriqueciendo y adornando su imitación del género caballeresco con todo tipo de tópicos, estilos y registros más o menos relacionados con él, y en muchos casos, no relacionados en absoluto: el romancero, la tradición ariostesca, la épica antigua, las crónicas españolas, la poesía y prosa pastoriles, los tópicos predilectos del humanismo renacentista, la lírica española y la italiana, los términos comerciales y legales, los giros coloquiales, con un largo etcétera. La novela de Cervantes se parece a una enorme esponja aplicada a la literatura y folclore anterior, absorbiendo sus motivos de modo casi imperceptible; la posteridad, al estrujar la esponja, se percata del poder sugestivo pero ya no percibe las referencias concretas, y por tanto suministra las que se le antojan. El epitafio de Cervantes bien pudiera ser aquello de Madame de Pompadour: "Après nous, le déluge".

${ }^{23}$ Véase mi Cervantes and the Comic Mind of his Age (Oxford University Press, 2000), pp. 96-100, y en especial, p. 99. 